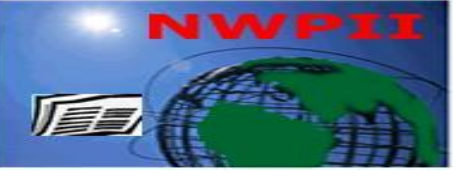

American Journal of Biomedical Sciences

ISSN: 1937-9080

nwpii.com/ajbms

\title{
Modeling Neuron for Simulation of Transmitter Gated Ion Channels of Postsynaptic Membrane at Synaptic Cleft
}

\author{
Jiten Ch. Dutta, Soumik Roy \\ Department of ECE, Tezpur University (a Central University), Napaam Post, Tezpur, Assam, India \\ *Corresponding Author \\ Soumik Roy \\ Dept of ECE, Tezpur University \\ Napaam Post, Tezpur \\ Assam - 784 028, India \\ Email: jitend@tezu.ernet.in (Jiten Ch. Dutta), xoumik@yahoo.com (Soumik Roy) \\ Received: 8 August 2010; | Revised: 8 March 2011; | Accepted: 25 March 2011

\begin{abstract}
The variable conductance of postsynaptic membrane of neuron dependence on the neurotransmitterreceptor binding activity is represented by ion sensitive field effect transistor (ISFET). ISFET functions not only as a voltage controlled conductance but can also be converted into an enzyme modified field effect transistor (ENFET) and therefore can provide a means of measurement of specific neurotransmitters that bind with the receptor sites of postsynaptic membrane. This analog is incorporated into the Hodgkin-Huxley $(\mathrm{H}-\mathrm{H})$ model of neuron to substitute the variable $\mathrm{Na}^{+}$and $\mathrm{Cl}^{-}$conductances. Simulation is performed in MATLAB environment both for excitatory and inhibitory states and results are presented.
\end{abstract}

Keywords: Neuron, Synapse, ISFET, ENFET, Postsynaptic membrane.

\section{Introduction}

Modeling of neuron has played an important role in the field of biomedical engineering and neurology for simulation of receptor function and electrical activity of the postsynaptic neuron.

The primary mode of communication between two neurons is a biochemical process that occurs at synapse. Synapse is essentially a junction called synaptic cleft between two neurons namely presynaptic and postsynaptic neurons. Signal from presynaptic neuron to postsynaptic neuron is transmitted through neurotransmitters released by presynaptic neuron into the synaptic cleft.
Neurotransmitters diffuse through the cleft and then bind with the specific receptor sites of the membrane of postsynaptic neuron. This binding mechanism initiates the opening of transmitter gated ion channels resulting in to flow of ions into the cell or out of the post synaptic cell.

The membrane of post synaptic neuron has two types of ion channels - excitatory and inhibitory. The excitatory channels are those which are specific to sodium ions and inhibitory channels are those which are specific to Chloride ions. The flow of Sodium ions into the cell causes a membrane potential called excitatory postsynaptic membrane potential (EPSP) whereas 
the flow of Chloride ions causes an inhibitory postsynaptic membrane potential (IPSP).

Many electronic circuits have been developed in the past to reproduce the behavior of nerve axons [1]-[5]. A very good account of this type of modeling is reviewed by Harmon et al [6] and Lewis [7]. But among these models, neuroscientists have so far utilized HodgkinHuxley $(\mathrm{H}-\mathrm{H})$ model as a circuit analog of the axonal membrane. The $\mathrm{H}-\mathrm{H}$ equations are simple and elegant tool, capable of explaining the activity of neuron with the help of variable permeability of membrane for different ions, e.g., sodium, potassium, chloride etc. But this model has not explained the function of synapses on which the variable permeability of postsynaptic membrane arises. In this work, an analog circuit model has been developed to simulate the function of neurotransmitter gated ion channels of postsynaptic membrane at the synaptic cleft. Simulation is performed in MATLAB environment both for excitatory and inhibitory actions of synapses.

\section{Hodgkin-Huxley Membrane Model}

Hodgkin and Huxley $(\mathrm{H}-\mathrm{H})$ have conducted a series of experiments to study in great detail the properties of postsynaptic membrane. From these experimental results, they have proposed an equivalent circuit to account for the resistive and capacitive properties of a patch of membrane [8]. This circuit is known as Hodgkin and Huxley $(\mathrm{H}-$ $\mathrm{H})$ model, which is shown in Fig. 1. In this model the capacitance of the lipid bilayer is represented by $C_{M}$ and has been found to be constant. The membrane resistance is determined in terms of parallel conductances $g_{N a}, g_{K}, g_{C l}$, and $g_{o}$, where the conductances $g_{N a}, g_{K}, g_{C l}$, and $g_{o}$ represent the membrane permeability of Sodium, Potassium, Chloride and other ions respectively. The $g_{K}$ and $g_{N a}$ conductances were found to be time and voltage dependent. $E_{N a}, E_{C l}$, and $E_{K}$ are the chemical potentials of Sodium, Chloride and Potassium respectively. $E_{O}$ is the resting potential.

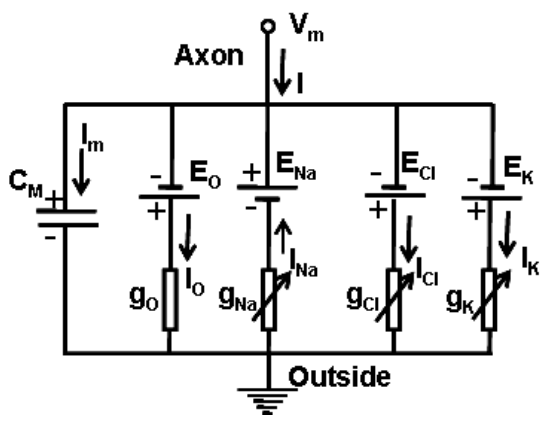

Figure.1: H-H model

In this model, the total current is given by

$$
\mathrm{I}=\mathrm{I}_{\mathrm{m}}+\mathrm{I}_{\mathrm{o}}-\mathrm{I}_{\mathrm{Na}}+\mathrm{I}_{\mathrm{Cl}}+\mathrm{I}_{\mathrm{K}}
$$

If $V_{m}$ be the postsynaptic membrane potential established by the ionic and capacitive membrane current then application of Kirchhoff's Current Law (KCL) yields-

$$
\begin{aligned}
\mathrm{I}= & \mathrm{C}\left(\mathrm{dV}_{\mathrm{m}} / \mathrm{dt}\right)+\mathrm{g}_{\mathrm{O}}\left(\mathrm{V}_{\mathrm{m}}-\mathrm{E}_{\mathrm{O}}\right)-\mathrm{g}_{\mathrm{Na}}\left(\mathrm{V}_{\mathrm{m}}-\mathrm{E}_{\mathrm{Na}}\right) \\
& +\mathrm{g}_{\mathrm{Cl}}\left(\mathrm{V}_{\mathrm{m}}-\mathrm{E}_{\mathrm{Cl}}\right)+\mathrm{g}_{\mathrm{K}}\left(\mathrm{V}_{\mathrm{m}}-\mathrm{E}_{\mathrm{K}}\right)
\end{aligned}
$$

Equations (1) and (2) are called $\mathrm{H}-\mathrm{H}$ equations which can be used to explain the activity of neuron.

\section{Modeling Theory of Neurotransmitter Gated Ion channels}

The communication between two neurons is one directional communication. The function of postsynaptic neuron may, therefore, be considered to be an input to the next neuron. Modeling of neuron is, therefore, performed for postsynaptic neuron.

The postsynaptic membrane consists of a lipid bilayer and transmembrane protein ion channels. Some ion channels such as sodium, chloride etc. are controlled by the neurotransmitters that bind with the receptor sites, i.e. the amount of ionic current is dependent upon the activity of the transmitter-receptor binding. In simplest case, the binding reaction may be represented as

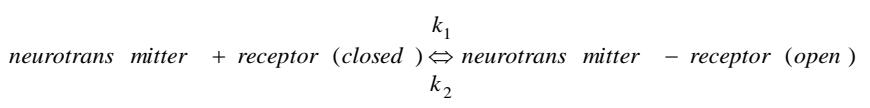

Where $k_{1}$ and $k_{2}$ are the forward and backward rate constants respectively. The transmitter gated channels, therefore, have 
variable conductance dependence on the binding activity of neurotransmitters.

Ion Sensitive Field Effect Transistor (ISFET) is in fact a Metal Oxide Semiconductor Field Effect Transistor (MOSFET) in which metal gate is replaced by a complex structure sensitive to hydrogen ion concentration. The schematic representation of an ISFET is given in Fig.2, as well as its electronic diagram. The details of such device can be obtained in literature [9].

(a)

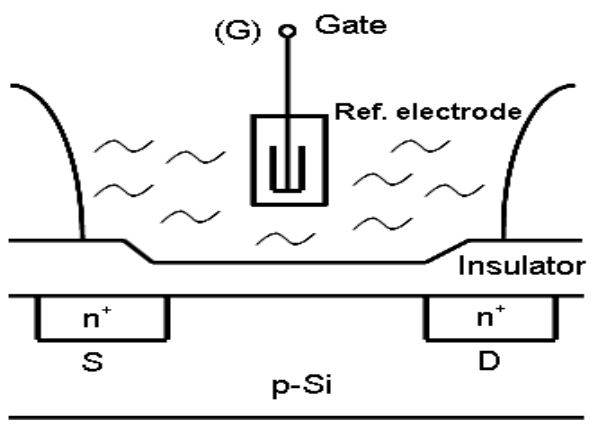

(b)

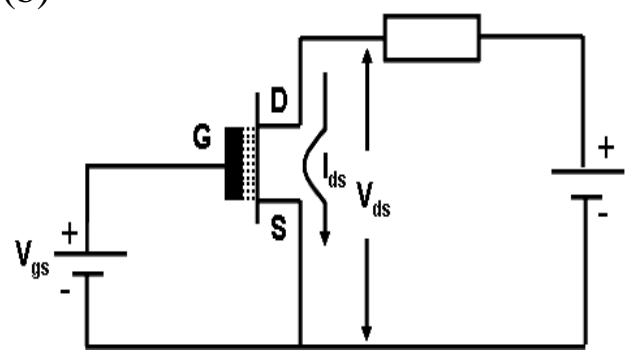

Figure 2 (a): ISFET; (b) Electronic Diagram

The threshold voltage of ISFET is given by

$V_{T H(I S)}=E_{r e f}-\psi_{0}+\chi^{s o l}-\phi_{S i}-\frac{Q_{o x}+Q_{s s}+Q_{B}}{C_{o x}}+2 \phi_{f}$

where, $2 \Phi_{f}$ is the semiconductor surface inversion potential, $\Phi_{f}$ is the Fermi potential of the semiconductor, $Q_{B}$ is the semiconductor depletion charge per unit area, $\Phi_{S i}$ is the work function of bulk semiconductor, $Q_{s s}$ is the fixed surface- state charge per unit area at the insulatorsemiconductor interface, $Q_{o x}$ is the accumulated charge in the oxide, $\Psi_{0}$ is the surface potential and can be shown to be a function of $\mathrm{pH}, \chi^{\text {sol }}$ is the surface dipole potential, $C_{O x}$ is the oxide capacity per unit area and $E_{r e f}$ is the reference electrode potential.

For a particular ISFET, $\Phi_{f}, Q_{B}, \Phi_{S i}, Q_{s s}, C_{o x}$, $Q_{o x}, \chi^{\text {sol }}$ and $E_{\text {ref }}$ are constants, $V_{T H(I S)}$ is dependent on the interfacial potential, $\Psi_{0}$. And since $\Psi_{0}$ is a function of $\mathrm{pH}$ and therefore $V_{T H}$ is also a function of $\mathrm{pH}$ i.e., $V_{T H}=f(p H)$.

For very small value of drain to source voltage, $V_{d s}$, the conductance of ISFET in its linear region can be expressed as [10]

$$
\mathrm{G}_{\mathrm{ds}}=\beta\left(\mathrm{V}_{\mathrm{gs}}-\mathrm{V}_{\mathrm{TH}(\mathrm{IS})}\right)
$$

$\beta$ is the geometric sensitivity parameter given by

$$
\beta=\mu C_{o x} \frac{W}{L}
$$

Where $W$ and $L$ are the width and the length of the channel respectively, and $\mu$ is the electron mobility in the channel. $V_{g s}$ is the voltage applied to the reference electrode. In ISFET, $\beta$ and $V_{g s}$ are constants and $V_{T H}(I S)$ is the only input variable. Thus $G_{d s}$ is dependent on the threshold voltage, $V_{T H(I S)}$, analogous to the conductance of ion channels of postsynaptic membrane dependent on the binding activity. Thus, considering the transmitter-receptor binding activity, the $\mathrm{H}-\mathrm{H}$ model for postsynaptic membrane can be modified as shown in Fig 3. Here $V_{g N}$ and $V_{g L}$ are fixed gate voltages applied to the reference electrodes of ISFETs and $V_{T H 1}$ and $V_{T H 2}$ are the respective threshold voltages of ISFETs that control the conductances $g_{N a}$ and $g_{C l}$ respectively.

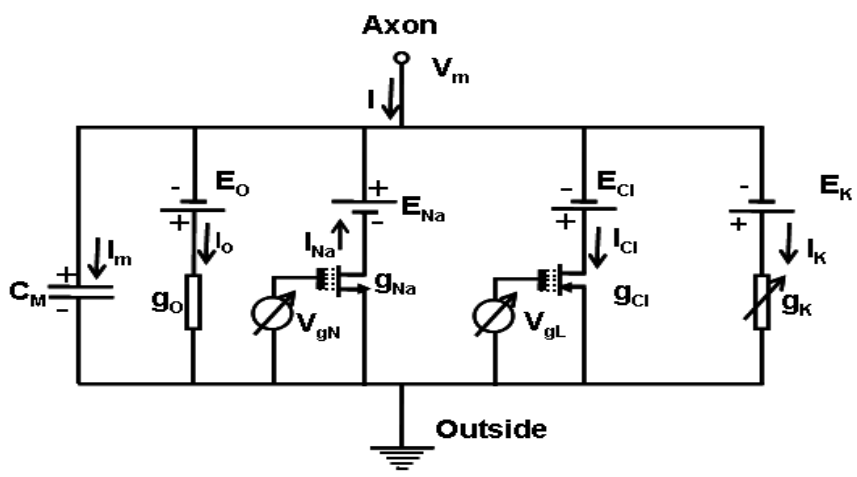

Figure 3: Modified H-H model of Postsynaptic membrane 
Neurotransmitter-receptor binding activity is a time dependent phenomenon and therefore number of opening of transmitter gated ion channels will be varying with respect to time. $V_{T H(I S)}$ in equation (5) can, therefore, be modeled as [11]-[12]:

$$
\mathrm{V}_{\mathrm{TH}(\mathrm{IS})}(\mathrm{t})=\mathrm{V}_{\mathrm{THO}}\left[\left(1-\exp \left(-\mathrm{k}_{1} \mathrm{t}\right)+\exp \left(-\mathrm{k}_{2} \mathrm{t}\right) \mathrm{U}\left(\mathrm{t}-\mathrm{t}_{\mathrm{m}}\right)\right]\right.
$$

Where $k_{1}$ and $k_{2}$ are time constants analogous to the rate constants of equation (3), $U\left(t-t_{m}\right)$ is the Heaviside function and $V_{T H O}$ is the threshold voltage proportional to the maximum attainable conductance, when all the transmitter-gated channels for specific ions are open.

\section{Modeling Neuron for Excitatory Synapse}

The modeling for excitatory synapse is shown in Fig 4. The leakage current $I_{o}$ is considered to be small enough to be neglected. Since only sodium channels are responsible for excitatory action, the postsynaptic membrane is divided into three patches to represent spatial summation of the sodium current controlled by $g_{N a_{1}}, g_{N_{2}}$, and $g_{N a_{3}}$, where

$$
I_{N a}=I_{1}+I_{2}+I_{3}
$$

So that, $I=I_{m}-I_{N a}+I_{K}$

$$
=C_{m} \frac{d V_{m}}{d t}-g_{N a}\left(V_{m}-E_{N a}\right)+g_{K}\left(V_{m}-E_{K}\right)
$$

Where $g_{N a}=g_{N a_{1}}+g_{N a_{2}}+g_{N a_{3}}$ and $g_{K}$ is the total Potassium conductance.

The membrane potential $V_{m}$ is obtained by spatially and temporally varying $g_{N a}$ of transmitter-gated sodium channels.

The component values assigned in the model for MATLAB simulation are taken from reference [11] and are given in Table 1. The specifications for three n-channel ISFETs as well as the parameters for exponential function in equation (7), applied to each ISFET inputs are also given in Table 1. The three gate to source voltages of three ISFETs i.e., $V_{g 1}, V_{g 2}$ and $V_{g 3}$ are kept constants at 1 Volt each. The three input parameters of ISFETs namely $V_{T H 1}, V_{T H 2}$ and $V_{T H 3}$ are applied in a staggered sequence at $1.5 \mathrm{msec}$ intervals. This is done to simulate the time variation in neurotransmitter-receptor binding with respect to different patches of postsynaptic membrane in accordance with reference [12] and [13].

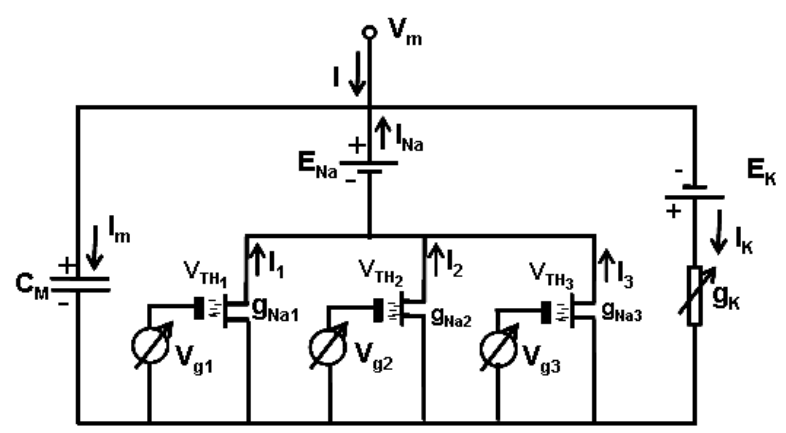

Figure 4: ISFET based Circuit model for excitatory action of synapse

\section{Modeling Neuron for Inhibitory Synapse}

The modeling for inhibitory synapse is shown in Fig 5. Considering only $\mathrm{Cl}^{-}$channels to be responsible for inhibitory action, the post synaptic membrane is divided into three patches to represent spatial summation of the Chloride current controlled by $g_{\mathrm{Cl}_{1}}, g_{\mathrm{Cl}_{2}}$ and $g_{\mathrm{Cl}_{3}}$, where

$$
I_{C l}=I_{1}+I_{2}+I_{3}
$$

So, that, $I=I_{m}+I_{C l}+I_{K}$

$$
=C_{m} \frac{d V_{m}}{d t}+g_{C l}\left(V_{m}-E_{C l}\right)+g_{K}\left(V_{m}-E_{K}\right)
$$

Where $g_{C l}=g_{C l_{1}}+g_{C_{2}}+g_{C l_{3}}$ and $g_{K}$ is the total Potassium conductance.

The membrane potential $V_{m}$ is obtained by spatially and temporally varying $g_{C l}$ of transmittergated Chlorine channels.

Table 1 summarizes the component values assigned in the model for MATLAB simulation for inhibitory action of synapse. The specifications for three p-channel ISFETs as well as the parameters for exponential function in equation (7), applied to each ISFET inputs are also given in Table 1. The three gate to source voltages of three ISFETs i.e $V_{g 1}, V_{g 2}$ and $V_{g 3}$ are kept constants at 1 Volt each. The three input parameters of ISFETs namely $V_{T H 1}, V_{T H 2}$ and $V_{T H 3}$ are applied in a staggered sequence at $1.5 \mathrm{msec}$ intervals. This is 
done to simulate the time variation in neurotransmitter -receptor binding with respect to different patches of postsynaptic membrane.

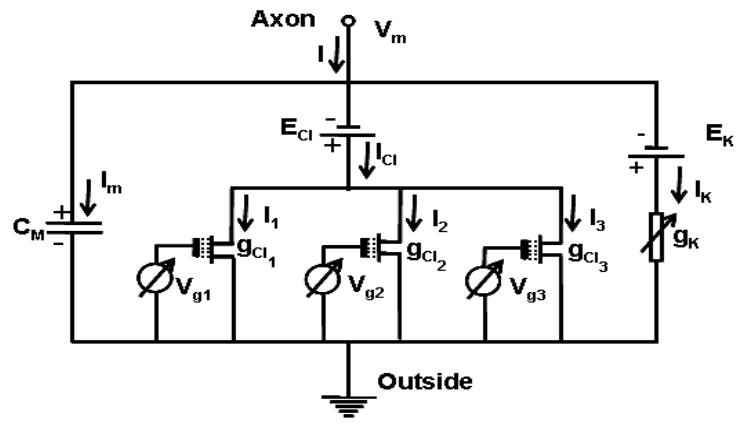

Fig.5: ISFET based Circuit model for inhibitory action of synapse

Table 1: Values of Parameters used in the simulation

\begin{tabular}{|c|c|c|c|c|c|c|c|}
\hline \multicolumn{4}{|c|}{ Excitatory Synapse } & \multicolumn{4}{|c|}{ Inhibitory Synapse } \\
\hline Parameter & Parameter Details & Unit & Value & Parameter & Parameter Details & Unit & Value \\
\hline $\mathrm{C}_{\mathrm{M}}$ & Membrane Capacitance & Farad & $1 \mu \mathrm{F}$ per $\mathrm{cm}^{2}$ & $\mathrm{C}_{\mathrm{M}}$ & Membrane Capacitance & Farad & $1 \mu \mathrm{F}$ per $\mathrm{cm}^{2}$ \\
\hline $\mathrm{g}_{\mathrm{K}}$ & Potassium Conductance & Mho & $1 \mathrm{mS}$ per $\mathrm{cm}^{2}$ & $\mathrm{~g}_{\mathrm{K}}$ & Potassium Conductance & Mho & $1 \mathrm{mS}$ per $\mathrm{cm}^{2}$ \\
\hline $\mathrm{E}_{\mathrm{Na}}$ & Sodium Potential & Volt & $60 \mathrm{mV}$ & $\mathrm{E}_{\mathrm{Cl}}$ & Chloride Potential & Volt & $-100 \mathrm{mV}$ \\
\hline$\overline{\mathrm{E}_{\mathrm{K}}}$ & Potassium Potential & Volt & $-90 \mathrm{mV}$ & $\overline{\mathrm{E}_{\mathrm{K}}}$ & Potassium Potential & Volt & $-90 \mathrm{mV}$ \\
\hline I & Membrane Current & Ampere & $0 \mathrm{~A}$ & I & Membrane Current & Ampere & $0 \mathrm{~A}$ \\
\hline $\bar{L}$ & Channel Length & Meter & $15 \mu \mathrm{m}$ & $\overline{\mathrm{L}}$ & Channel Length & Meter & $15 \mu \mathrm{m}$ \\
\hline$\overline{\mathrm{W}}$ & Channel Width & Meter & $2 \mu \mathrm{m}$ & $\mathrm{W}$ & Channel Width & Meter & $2 \mu \mathrm{m}$ \\
\hline $\mathrm{t}_{\mathrm{ox}}$ & Oxide Thickness & Meter & $100 \mathrm{~nm}$ & $\mathrm{t}_{\mathrm{Ox}}$ & Oxide Thickness & Meter & $100 \mathrm{~nm}$ \\
\hline$\mu$ & Electron mobility & $\mathrm{cm}^{2} / \mathrm{V}$-sec & $600 \mathrm{~cm}^{2} / \mathrm{V}$-sec & $\mu$ & Electron mobility & $\mathrm{cm}^{2} / \mathrm{V}$-sec & $600 \mathrm{~cm}^{2} / \mathrm{V}$-sec \\
\hline $\mathrm{V}_{\mathrm{THO}}$ & Threshold Voltage & Volt & -2 Volts & $\mathrm{V}_{\mathrm{THO}}$ & Threshold Voltage & Volt & 5 Volts \\
\hline $\mathrm{t}_{\mathrm{m}}$ & Time & Second & $600 \mu \mathrm{sec}$ & $\mathrm{t}_{\mathrm{m}}$ & Time & Second & $850 \mu \mathrm{sec}$ \\
\hline $\mathrm{k}_{1}=\mathrm{k}_{2}$ & Time Constant & Second & $0.8 \mathrm{msec}$ & $\mathrm{k}_{1}=\mathrm{k}_{2}$ & Time Constant & Second & $0.8 \mathrm{msec}$ \\
\hline
\end{tabular}

Table 2: Comparison of Simulation Results

\begin{tabular}{|c|c|c|c|c|c|c|c|}
\hline \multicolumn{4}{|c|}{ Excitatory } & \multicolumn{4}{|c|}{ Inhibitory } \\
\hline Sl. No. & $\begin{array}{c}\text { Threshold limit to } \\
\text { initiate action potential }\end{array}$ & $\begin{array}{c}\text { Time to } \\
\text { attain peak } \\
\text { value }\end{array}$ & $\begin{array}{l}\text { Total duration } \\
\text { of EPSP }\end{array}$ & Sl. No. & $\begin{array}{c}\text { Threshold limit to } \\
\text { initiate action potential }\end{array}$ & $\begin{array}{c}\text { Time to } \\
\text { attain peak } \\
\text { value }\end{array}$ & $\begin{array}{l}\text { Total duration } \\
\text { of IPSP }\end{array}$ \\
\hline $\begin{array}{l}\text { Ref. [11] } \\
\end{array}$ & $-60 \mathrm{mV}$ to $-40 \mathrm{mV}$ & $1 \mathrm{~ms}$ & $3.7 \mathrm{~ms}$ & Ref. [11] & No Action Potential & $1.5 \mathrm{~ms}$ & $3 \mathrm{~ms}$ \\
\hline Ref. [12] & $-60 \mathrm{mV}$ to $-40 \mathrm{mV}$ & $3 \mathrm{~ms}$ & $6 \mathrm{~ms}$ & Ref. [12] & Simulation performe & only for excita & y synapse \\
\hline Ref. [13] & $-65 \mathrm{mV}$ to $-50 \mathrm{mV}$ & $1 \mathrm{~ms}$ & $3.5 \mathrm{~ms}$ & Ref. [13] & No Action Potential & $1.2 \mathrm{~ms}$ & $3.5 \mathrm{~ms}$ \\
\hline Present Work & $-60 \mathrm{mV}$ to $-40 \mathrm{mV}$ & $1 \mathrm{~ms}$ & $3.5 \mathrm{~ms}$ & Present Work & No Action Potential & $1.5 \mathrm{~ms}$ & $3 \mathrm{~ms}$ \\
\hline
\end{tabular}

\section{Results}

The MATLAB simulation outputs are shown in Fig. 6. The top waveform represents the normal postsynaptic membrane potential. Here $V_{m}$ is established by spatial summation and temporal integration of the transmitter gated sodium current and non-gated potassium current. Simulation results indicate that when $V_{m}$ exceeds a threshold in the range of -60 to $-40 \mathrm{mV}$, an action potential initiates which illustrates an EPSP. The bottom waveform represents the inhibitory action. It illustrates an IPSP with sufficient amplitude for triggering an action potential in negative direction. The simulated EPSP and IPSP are very similar to the experimentally recorded ones i.e., with real excitatory and inhibitory actions of post synaptic membrane. 
Fig. 7 shows the simulation results of excitatory and inhibitory actions of postsynaptic membrane using MOSFET, the details of which can be obtained in reference [11]. In this work, the variable conductance of ion channel is represented by MOSFET. Unlike ISFET, the threshold voltage, $V_{T H}$ of MOSFET is kept constant and the gate voltage $V_{g s}$ is taken as input parameter. The close similarity between the two results indicates that ISFET can be used as circuit analog to simulate the excitatory and inhibitory postsynaptic potentials. The results obtained from simulation using ISFET are also compared with those reported by previous researchers and are given in Table 2.

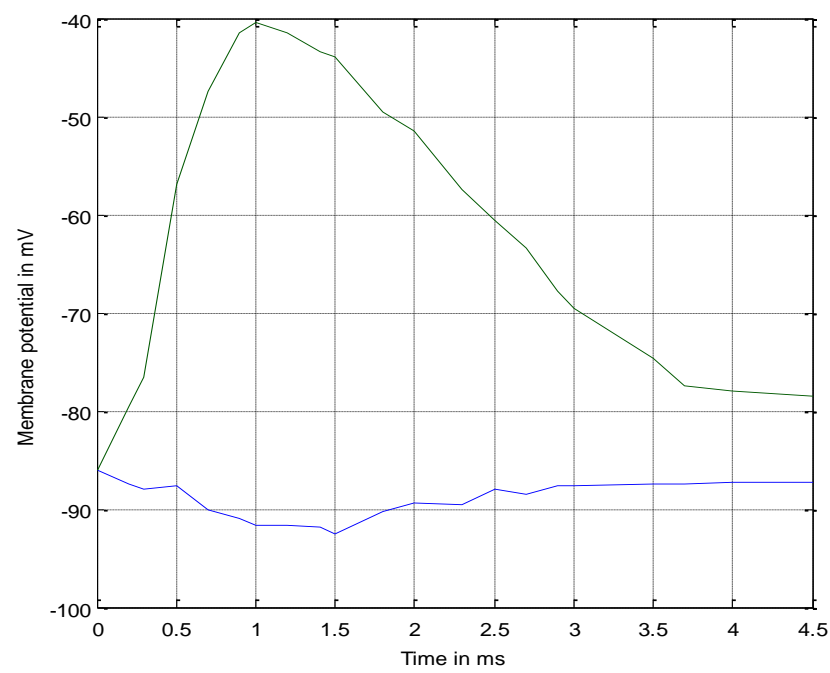

Figure 6: Simulation results of excitatory and inhibitory actions of postsynaptic membrane. Top waveform represents the EPSP and bottom waveform represents the IPSP. This is obtained by representing the variable conductance of ion channels with ISFET where gate voltage $V_{g s}$ is constant and threshold voltage, $V_{T H}$ is the input parameter in accordance with the equations (5) and (7).

\section{Conclusion}

ISFET based electrical models both for excitatory and inhibitory actions of neurons have been developed. Postsynaptic membrane is divided into three patches to represent spatial summation of gated currents. Temporal integration of the currents is achieved by modeling exponentially varying time dependent threshold voltage of ISFET. The main aim of this work is to show that ISFET can be used as circuit analog to simulate the excitatory and inhibitory postsynaptic potentials with an additional advantage: possibility of measurement of neurotransmitters diffused through the synaptic cleft by converting the ISFET into neurotransmitter sensitive ENFET [14]-[15] This biologically motivated model may become a useful research and teaching unit both in neurology and bioelectronics areas.

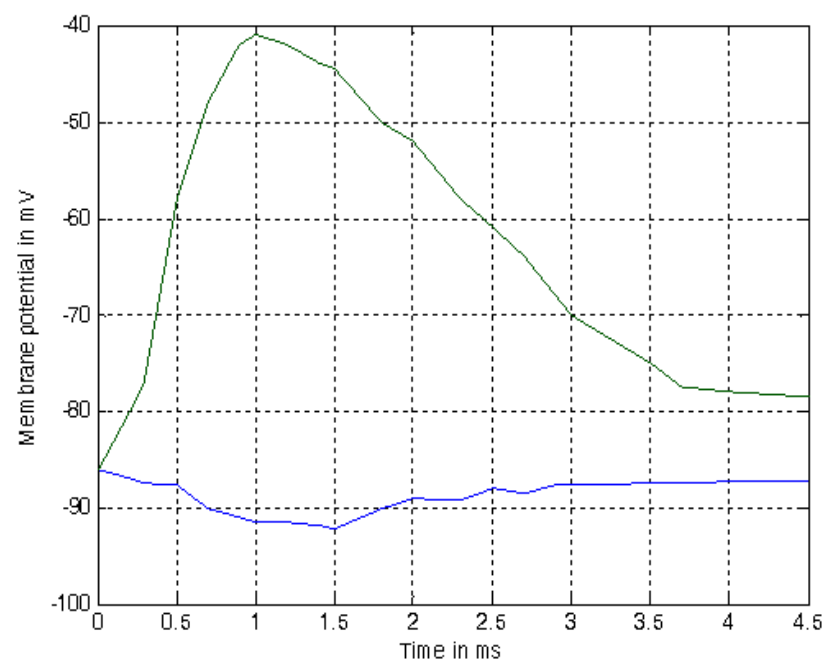

Figure 7: Simulation results of excitatory and inhibitory actions of postsynaptic membrane using MOSFET [11].

\section{Acknowledgement}

The authors wish to thank UGC for their support to innovative programme "Bioelectronics" and AICTE for their support to Neurobioengineering research.

\section{BIOGRAPHY}

Jiten Ch. Dutta was born in Assam, India, in 1963. He received his M.E and Ph. D degrees in Engineering from Jadavpur University, India, in 1994 and 2001 respectively. He has joined the Dept. of Electronics and Communication Engineering, Tezpur University in 2000 and presently serving as Associate Prof. He is the founder of Bioelectronics programme at Tezpur University supported by UGC under its innovative scheme and has set up a Laboratory in a new area "Neuorobioengineering". He is actively involved 
with the B. Tech program in Electronics and Communication Engineering department of Tezpur University and prepared the course syllabi for the same. His research interests include Modeling ISFETs, Neurobioengineering, Bioelectronics and optical fiber sensors.

Soumik Roy was born in Assam, India, in 1973. He received his $M$. Tech degree in Electronics Design \& Technology from Tezpur University, India, in 2000 and presently pursuing his $\mathrm{Ph} \mathrm{D}$ in the field of Neurobioengineering from Tezpur University under the guidance of Dr Jiten Ch. Dutta. He has joined the Dept. of Electronics and Communication engineering, Tezpur University, in 2003 and presently serving as Assistant Professor. $\mathrm{He}$ is actively involved with the innovative program, $M$. Tech in Bioelectronics at Tezpur University and is instrumental to set up Laboratory in a new area "Neurobioengineering".

\section{References}

[1] Hodgkin, A. L.; Huxley, A. F. A quantitative description of membrane current and its application to conduction and excitation in nerve, J. Physiol, 117. 500-544(1952).

[2] Hodgkin, A. L. Ionic movements and electrical activity in giant nerve fibers, Proceedings of the Royal Society of London. Series B, Biological Sciences, Vol. 148, 1-38(1957)

[3] Fitzhugh, R. Threshold and plateaus in the Hodgkin-Huxley nerve equations, J. Gen. Physiology, 43, 867-(1960)

[4] Johnson; Hanna. Membrane model: A single transistor analog of excitable membrane, $J$. Theoret. Bio, 22, 401-411(1969). DOI:10.1016/0022-5193(69)90012-5

[5] Lewis, E. R. Neuroelectric potentials derived from an extended version of the Hodgkin and Huxley model, J. Theor. Biol. Vol.10,125-158, 1965. DOI:10.1016/0022-5193(66)90181-0

[6] Harmon, L. D.; Lewis, E. R. Neural modeling, Physiol. Rev., Vol. 48, 513-591, 1966

[7] Lewis, E. R. Using electronic circuits to model simple neuroelectric interactions, Proc. IEEE, vol. 56, 931-949, June 1968. DOI: 10.1109/PROC.1968.6445

[8] Guy; R. A simple Electronic Analog of the Squid Axon Membrane: The NEUROFET, IEEE Transaction on Biomedical Engineering, Vol. BME-19, Issue: 1, 60-63, 1972. DOI: 10.1109/TBME.1972.324161

[9] Bergveld, P. Thirty years of ISFETOLOGY what happened in the past and what may happen in the next thirty years, Sensors and Actuators $\quad B, \quad 88 \quad$ (2003),1-20. DOI:10.1016/S0925-4005(02)00301-5

[10] Gratarola, M.; Massobrio, G; Bioelectronics Handbook: MOSFETs, Biosensors, \& Neurons; McGraw Hill, 1998

[11] Dutta, Jiten Ch.; Roy, Soumik. Biologically Motivated Circuit Model for Simulation of Excitatory and Inhibitory Synapses, Canadian Journal on Biomedical Engineering \& Technology, Vol. 1, No. 2 June 2010, 49-51.

[12] Levine, M. D.; Eisenberg, M. F.; Fare, T. L. A Physiologic-Based Circuit Model of the Postsynaptic region at the Neuromuscular Junction, IEEE Proceedings, pp. 1602 - 1603, ISBN : 0-7803-0785-2. DOI: 10.1109/IEMBS.1992.589827

[13] Levine, M. D.; Fare, T. L.; Eisenberg, M. F. A Physiologic Based Circuit Model of Excitation \& Inhibition in the postsynaptic region, IEEE Proceedings of the $35^{\text {th }}$ Midwest Sysmposium on Circuits \& Systems., pp. 268269, Vol-I, ISBN : 0-7803-0510-8. DOI: 10.1109/MWSCAS.1992.271383

[14] Kharitonov, A. B.; et al. Enzyme monolayerfunctionalized field- effect transistors for biosensor applications, Sensors and Actuators $B$, 70, 222-231, 2000. DOI: 10.1016/S09254005(00)00573-6

[15] Dutta, Jiten. Ch.; Roy, Soumik. Biologically inspired Circuit model for simulation of Acetylcholine gated ion channels of the Postsynaptic membrane at synaptic cleft, Proc. 2010 IEEE-EMBS Conference on Biomedical Engineering and Sciences, IECBES2010, Nov 30 - Dec'02,2010. 